TITLE:

\title{
Analysis of the correlation between $n$-value and critical current in bent multifilamentary Bi2223 composite tape based on a damage evolution model
}

\section{AUTHOR(S):}

Ochiai, S; Okuda, H; Fujimoto, M; Shin, J-K; Sugano, M; Hojo, M; Osamura, K; Oh, S S; Ha, D W

\section{CITATION:}

Ochiai, S ... [et al]. Analysis of the correlation between n-value and critical current in bent multifilamentary Bi2223 composite tape based on a damage evolution model.

Superconductor Science and Technology 2012, 25(5): 054016.

\section{ISSUE DATE:}

2012-04

URL:

http://hdl.handle.net/2433/155798

\section{RIGHT:}

(C) IOP Publishing 2012.; This is not the published version. Please cite

only the published version.; この論文は出版社版でありません。引用の 際には出版社版をご確認ご利用ください。 


\title{
Analysis of Correlation between $\boldsymbol{n}$-value and Critical Current in Bent Multifilamentary Bi2223 Composite Tape Based on Damage Evolution Model
}

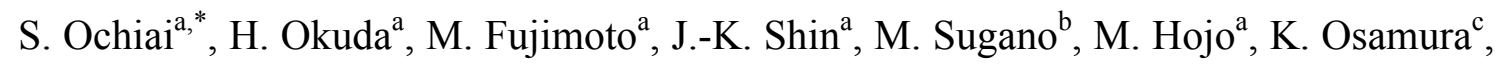
S. S. Oh ${ }^{\mathrm{d}}$ and D. W. $\mathrm{Ha}^{\mathrm{d}}$

a Graduate School of Engineering, Kyoto University, Yoshida, Sakyo-ku, Kyoto 606-8501, Japan.

${ }^{b}$ High Energy Accelerator Research Organization (KEK), Cryogenics Science Center, J-PARC Center, 203-1 Shirakata, Tokai-Mura, Naka-gun, Ibaraki 319-1106, Japan.

${ }^{\mathrm{c}}$ Research Institute for Applied Sciences, Sakyo-ku, Kyoto 606-8202, Japan.

${ }^{d}$ Korea Electrotechnology Research Institute, 28-1 Sungju-Dong, Changwon 641-120, Korea

\begin{abstract}
The change in $n$-value and critical current with bending strain and the relation of $n$-value to critical current of bent-damaged Bi2223 composite tape were studied experimentally and analytically. The $n$-value of the bent-damaged $\mathrm{Bi} 2223$ filamentary composite tape decreased rather slightly with increasing bending strain and with decreasing critical current, in comparison with that of tension-damaged tape. To describe the experimental result of bent-damaged tape above, a damage evolution model was applied, in which the steep tensile strain-variation in the thickness direction, shape of the core in which superconducting filaments are bundled into and the damage strain parameters obtained from the analysis of the tensile stress-strain curve were incorporated. The measured change in $n$-value and critical current with bending strain and the relation of $n$-value to critical current under applied bending strain were described satisfactorily by the present approach.
\end{abstract}

PACS codes: $74.25 \mathrm{~Sv} ; 74.25 \mathrm{Ld}$

Keywords: Bi2223 composite tape; Critical current; $n$-value; Bending strain; Damage evolution 
*Corresponding author.

Prof. Shojiro Ochiai

Postal address: Department of Materials Science and Engineering, Graduate School of

Engineering, Kyoto University, Yoshida, Sakyo-ku, Kyoto 606-8501, Japan

Phone: +81 757534834

Fax: +81757534841

E-mail address: shojiro.ochiai@materials.mbox.media.kyoto-u.ac.jp 


\section{Introduction}

$(\mathrm{Bi}, \mathrm{Pb})_{2} \mathrm{Sr}_{2} \mathrm{Ca}_{2} \mathrm{Cu}_{3} \mathrm{O}_{10+\delta}$ (Bi2223) composite superconductor tapes have been developed for high in-field applications, such as magnets and motors [1]. They are subjected to stresses such as (a) residual stresses arising from the mismatch of the coefficient of thermal expansion among the constituents, (b) tensile and bending stresses during winding to make coils and (c) electro-magnetic (Lorentz) force in operation [2-4]. The brittle Bi2223 filaments that transport superconducting current are damaged when the subjected stresses are high. Accordingly, it is needed to clarify the influence of damage evolution on the superconducting property for reliability and safe design. Until now, it has been revealed that, once the applied strain exceeds the irreversible strain at which damage initiates, the critical current never returns to the original value even when the applied strain is released, while it returns reversibly when the applied strain is lower than the irreversible strain [1-26]. Such a feature has been observed commonly under tensile and bending strain-application. On the other hand, the damage initiation and evolution behavior under tensile strain is different from that under bending strain, as follows.

Under application of tensile strain $\left(\varepsilon_{\mathrm{T}}\right)$, the weaker filaments within the gauge length are cracked in the early stage, and then the stress concentration arising from the cracked filaments causes collective cracks (cracks composed of successively cracked filaments in a transverse cross-section [7, 27]), reducing critical current seriously. Under application of bending strain $\left(\varepsilon_{\mathrm{B}}\right)$, filament-cracking is caused also mainly by the tensile strain in the sample length direction but its extent is dependent on location in sample thickness direction [14-16, 24-26]. The strain of Bi2223 filament $\varepsilon_{\mathrm{Bi} 2223}$ in the sample length direction, induced by applied bending strain, varies steeply along the thickness direction; it is equal to the residual strain $\left(\varepsilon_{\mathrm{r}}\right)$ at the neutral axis and it increases and decreases with distance from the neutral axis in the tensile- and compressive sides, respectively. The filaments at the positions apart from the neutral axis are cracked severely, while those at the position near the neutral axis are less cracked.

Due to the difference in damage evolution between tensile $\left(\varepsilon_{\mathrm{T}}\right)$ - and bending $\left(\varepsilon_{\mathrm{B}}\right)$-strain application, it is expected that the change in critical current and $n$-value with increasing applied strain and also the correlation of $n$-value to critical current are different. The aims of the present work are (i) to assure experimentally these expected features and (ii) to describe the experimental results under bending strain by modeling analysis from a viewpoint of damage evolution. 


\section{Experimental procedure}

\subsection{Sample}

The multifilamentary Bi2223/Ag/Ag alloy composite tape, fabricated at Korea Electrotechnology Research Institute (KERI), was used as the sample. It contained 55 Bi2223 filaments. The thickness $(t)$ and width $(W)$ of the sample were $0.23 \mathrm{~mm}$ and 4.1 $\mathrm{mm}$, respectively. The residual strain $\varepsilon_{\mathrm{r}}$ of Bi2223 filaments in this sample at room temperature has been estimated to be $-0.12 \%$ with an X-ray diffraction method [15]. Also it has been shown that, under applied bending strain $\varepsilon_{\mathrm{B}}$ up to $0.83 \%$, damage occurs only in the tensile side $[15,25]$.

\subsection{Procedure for measurement of critical current and $\boldsymbol{n}$-value}

As the damage behavior and hence critical current and $n$-value differ among test specimens $[24,25]$, many specimens are needed to extract the feature of the relation of $n$-value to critical current $\left(I_{\mathrm{c}}\right)$. In the present work, we used the test specimens with a configuration shown in Fig.1. Seven voltage probes were attached in a step of $1 \mathrm{~cm}$ in the test specimens with a length $6 \mathrm{~cm}$. The $V$ (voltage)- $I$ (current) curve was measured for 6 sections (S1 to $\mathrm{S} 6$ in Fig.1) with a length $L=1 \mathrm{~cm}$. Two test-specimens were used in experiment. Thus for totally 12 sections, $I_{\mathrm{c}^{-}}$and $n$-values were measured at each bending strain $\varepsilon_{\mathrm{B}}$ and the results were averaged for analysis.

Bending strain $\varepsilon_{\mathrm{B}}$ was given at room temperature by pressing the test specimens with the upper GFRP (Glass Fiber Reinforced Plastic) die to the lower one with the same curvature, similarly to the round robin test of VAMAS (Versailles project on advanced materials and standard)/TWA 16 (Technical working area 16, superconducting materials) [21]. Six pairs of dies with different curvatures were used and the specimens were bent by $\varepsilon_{\mathrm{B}}=0,0.19,0.39,0.52,0.67$ and $0.83 \%$. The specimens bent at room temperature were cooled down to $77 \mathrm{~K}$, at which $V-I$ curves were measured in a self magnetic field. The $V-I$ curve was approximated by

$$
V=L E_{\mathrm{c}}\left(I / I_{\mathrm{c}}\right)^{n}
$$

where $E_{\mathrm{c}}(=1 \mu \mathrm{V} / \mathrm{cm})$ is the electric filed criterion for critical current. $n$-value in Eq.(1) was estimated for the range of $V / L=0.1$ to $10 \mu \mathrm{V} / \mathrm{cm}$.

Also the specimens shown in Fig. 1 were pulled in tension at $77 \mathrm{~K}$ and the $V-I$ curves were measured at $77 \mathrm{~K}$ for 12 sections. Due to the difference in damage behavior among sections, the strains of sections are different to each other but stress is common for all 
sections. Due to this reason, stress is used instead of strain as a measure of applied mechanical condition. The tensile stress $\sigma_{\mathrm{T}}$ was given stepwise to test specimens up to $137 \mathrm{MPa}$. The $I_{\mathrm{c}^{-}}$and $n$-values under applied tensile stress were estimated in the same manner as those under applied bending strain.

\section{Measured critical current- and $n$-values, and correlation of $n$-value to critical current}

Figure 2 shows the change in (a) critical current $I_{\mathrm{c}}$ and (b) $n$-value with bending strain $\varepsilon_{\mathrm{B}}$ up to $0.83 \%$. The decrease in $n$-value (b) with increasing $\varepsilon_{\mathrm{B}}$ is rather slight in comparison with that in critical current (a). Such a slight decrease in $n$-value with increasing $\varepsilon_{\mathrm{B}}$ has been reported also for the different supplier's Bi2223 composite tape [21]. Figure 3 shows the change in (a) critical current $I_{c}$ and (b) $n$-value with tensile stress $\sigma_{\mathrm{T}}$. The decrease in $n$-value (b) with increasing tensile stress as well as that in critical current (a) is large above $120 \mathrm{MPa}$.

Figure 4 shows the comparison of the relation of $n$-value to critical current $I_{\mathrm{c}}$ measured under bending strain with that measured under tensile stress. The data under bending strain at $\varepsilon_{\mathrm{B}}=1.0 \%$ (open circles), measured for the same sample with the same procedure as in the present work, were taken from our former work [24]. The following features are read. (i) In the range of $I_{\mathrm{c}}>40 \mathrm{~A}$, the decrease in $n$-value with decreasing $I_{\mathrm{c}}$ under bending strain is small in comparison with that under tensile stress. (ii) When $I_{\mathrm{c}}$ becomes lower than $40 \mathrm{~A}$, the decrease in $n$-value with decreasing $I_{\mathrm{c}}$ under bending strain becomes very sharp. The reason for this could be attributed to the damage evolution in the compression side [24]. Otto et al. [12] reported that the buckling of the filaments occurs under compressive stress and the plural filaments are damaged at the same time by the buckling. At high bending strain such as $\varepsilon_{\mathrm{B}}=1.0 \%$ for the present sample, when compressive side is damaged in addition to tensile side, $n$-value decreases seriously due to the buckling fracture.

As shown above, under tensile stress, $n$-value decreases significantly with decreasing $I_{\mathrm{c}}$. In contrast, the slight decrease in $n$-value with increasing $\varepsilon_{\mathrm{B}}$ up to $0.83 \%$ and slight decrease in $n$-value with decreasing critical current up to $\varepsilon_{\mathrm{B}}=0.83 \%$ are the features in the case of bending strain application. Such a feature could be described below, by modeling analysis.

\section{Analysis of the experimental results by a damage evolution model under bending strain}


4.1 Estimation of damage strain parameters $\varepsilon_{f, 1}$ and $\varepsilon_{f, 2}$ from tensile stress $\left(\sigma_{\mathrm{T}}\right)$-strain $\left(\varepsilon_{\mathrm{T}}\right)$ curve at room temperature

In the present work, the specimens were bent at room temperature and were cooled down to $77 \mathrm{~K}$ at which critical current and $n$-value were measured. When the specimens are cooled to $77 \mathrm{~K}$, compressive strain is added to the Bi2223 filaments in the current transport direction due to the higher coefficient of thermal expansion of metallic constituents of $\mathrm{Ag}$ and $\mathrm{Ag}$ alloy than that of Bi2223 filaments [13, 15, 17]. As the damage of filaments in the bent specimens is caused by the tensile strain in the current transport direction, the filaments have been damaged by the bending-induced tensile strain at room temperature. The additionally exerted compressive strain on filaments at $77 \mathrm{~K}$ due to cooling does not cause further damage. The damage of the filaments at room temperature is conserved at $77 \mathrm{~K}$, and hence, the critical current at $77 \mathrm{~K}$ is determined by the damage at room temperature [15-17]. Due to this reason, the residual strain and the stress-strain curve at room temperature are used for analysis below.

As stated above, as bending strain was applied to specimens at room temperature, the damage was introduced at room temperature. Cracking of filaments is caused when the filament strain $\varepsilon_{\mathrm{Bi} 2223}$ in the longitudinal direction reaches its fracture strain. The $\varepsilon_{\mathrm{Bi} 2223}$ varies steeply in the sample thickness direction and hence the extent of damage is location-dependent, which is the cause of the slight decrease in $n$-value with decreasing $I_{\mathrm{c}}$, as shown later in Subsection 4.4. In this subsection, we estimate two damage strain parameters from the tensile stress-strain curve at room temperature, for modeling the location-dependent damage extent under bending stain. One refers to the tensile strain at initiation of damage $\left(\varepsilon_{\mathrm{Bi} 2223}=\varepsilon_{\mathrm{f}, 1}\right)$ and another to the tensile strain at which damage has occurred seriously $\left(\varepsilon_{\mathrm{Bi} 2223}=\varepsilon_{\mathrm{f}, 2}\right)$. These parameters will be used in the modeling and calculation in the subsequent subsections.

It has been shown $[5,7,13-16]$ that the tensile strain that causes cracking of the filaments is given by $\varepsilon_{\mathrm{f}}-\varepsilon_{\mathrm{r}}$ where $\varepsilon_{\mathrm{f}}$ is the tensile fracture strain of the bare Bi2223 filament and $\varepsilon_{\mathrm{r}}$ is the residual strain of the filaments in composite tape, arising during cooling down from heat-treatment- to room- temperature due to the difference in coefficient of thermal expansion among the constituents (Bi2223, Ag and Ag alloy) [13, $15,17]$. The residual strain $\varepsilon_{\mathrm{r}}$ of the present sample at room temperature has been estimated to be $-0.12 \%$ (compressive strain) with an X-ray diffraction method [15].

Under applied tensile strain (stress), the cracking occurs first in the weakest filament with the lowest $\varepsilon_{\mathrm{f}}-\varepsilon_{\mathrm{r}}$ value. Regarding the $\varepsilon_{\mathrm{r}}(-0.12 \%)$ to be common for all 
filaments and noting the lowest intrinsic fracture strain $\varepsilon_{\mathrm{f}, 1}$, we define the lowest $\varepsilon_{\mathrm{f}}-\varepsilon_{\mathrm{r}}$ value as $\varepsilon_{f, 1}-\varepsilon_{\mathrm{r}}$. This value corresponds to the irreversible strain under tension. Number of cracked filaments increases with increasing applied strain, leading to reduction in critical current. In the late stage, the surviving filaments that have high $\varepsilon_{\mathrm{f}}-\mathcal{E}_{\mathrm{r}}$ values in the cross-section in which filaments are most severely cracked, are also cracked, resulting in almost zero critical current. We note such a high $\varepsilon_{\mathrm{f}}-\varepsilon_{\mathrm{r}}$ value as $\varepsilon_{\mathrm{f}, 2}-\varepsilon_{\mathrm{r}}$. The values of $\varepsilon_{\mathrm{f}, 1}-\varepsilon_{\mathrm{r}}$ and $\varepsilon_{\mathrm{f}, 2}-\varepsilon_{\mathrm{r}}$ can be estimated from the tensile stress - strain curve by using the procedure in our preceding work [17], as follows.

Figure 5(a) shows the measured tensile stress $\left(\sigma_{\mathrm{T}}\right)$-strain $\left(\varepsilon_{\mathrm{T}}\right)$ curve of the sample at room temperature, which had been cooled down to $77 \mathrm{~K}$ for pre-check of critical current and then had been warmed up to room temperature at KERI. The stress-strain curve was analyzed in our preceding work by using the residual strain $(-0.12 \%)$ of Bi2223 filaments [15]. Silver is yielded in compression at $\varepsilon_{\mathrm{T}}=0 \%$ and is yielded in tension at $\varepsilon_{\mathrm{T}}=0.05 \%$. Ag alloy deforms elastically up to $\varepsilon_{\mathrm{T}}=0.12 \%$, at which $\mathrm{Ag}$ alloy is yielded in tension. Thus, all constituents of $\mathrm{Ag}, \mathrm{Ag}$ alloy and Bi2223 filaments deform elastically in the range of $0<\varepsilon_{\mathrm{T}}<0.05 \%$ (Stage I), Ag alloy and Bi2223 filaments deform elastically but $\mathrm{Ag}$ deforms plastically in the range of $0.05 \%<\varepsilon_{\mathrm{T}}<0.12 \%$ (Stage II), and only Bi2223 filaments deform elastically in the range of $0.12 \%<\varepsilon_{\mathrm{T}}$ (Stage III). In Stage III, cracking of filaments initiates and the number of cracked filaments increase with increasing applied tensile strain. With further increasing applied tensile strain $\left(\varepsilon_{\mathrm{T}}>\right.$ $0.25 \%$ in the present sample (Fig.5(a)), the sample deforms at nearly constant stress, where the loss of stress-bearing capacity due to multiple cracking of filaments (once-cracked filaments are continually cracked in other cross-sections) is balanced with the strain hardening-induced increase in stress carrying capacity of the Ag and Ag alloy $[7,15,17]$.

The filament cracking initiates in advance of such a stress-constant stage [7, 14, 17]. The stress-strain range, covering the cracking- initiation and -evolution stages and part of multiple cracking stage, is shown with a rectangle (Fig.5(a)). In this strain range, the cracked filaments cause reduction in Young's modulus and hence cause reduction in slope of the stress-strain curve. The variation of the slope $\mathrm{d} \sigma_{\mathrm{T}} / \mathrm{d} \varepsilon_{\mathrm{T}}$ with strain $\varepsilon_{\mathrm{T}}$ in such a stress-strain range is shown in Fig.5(b). $\varepsilon_{\mathrm{T}}$ is expressed as $\varepsilon_{\mathrm{T}}=\varepsilon_{\mathrm{Bi} 2223}-\varepsilon_{\mathrm{r}}$. At $\varepsilon_{\mathrm{T}}=0 \%$, the strain of the Bi2223 filaments $\varepsilon_{\mathrm{Bi} 2223}$ is equal to $\varepsilon_{\mathrm{r}}$ (compressive and therefore negative $[7,13,15,17])$. With increasing $\varepsilon_{\mathrm{T}}, \varepsilon_{\mathrm{Bi} 2223}$ becomes zero at $\varepsilon_{\mathrm{T}}=-\varepsilon_{\mathrm{r}}$ and becomes $\varepsilon_{\mathrm{f}}$ (fracture strain of bare filaments) at $\varepsilon_{\mathrm{T}}=\varepsilon_{\mathrm{f}}-\varepsilon_{\mathrm{r}}$. Thus, $\varepsilon_{\mathrm{f}, 1}-\varepsilon_{\mathrm{r}}$ (= the strain at initiation of filament cracking) can be estimated from the tensile strain $\varepsilon_{\mathrm{T}}$ at which the reduction in slope initiates. Here, it is noted that the strain hardening rate of the 
plastically deforming Ag and Ag alloy decreases gradually with increasing strain, which is a common feature of ductile metals. The slight decrease in slope up to $\varepsilon_{\mathrm{T}}=0.21 \%$ in Fig.5(b) is attributed to this phenomenon [17]. Beyond $\varepsilon_{\mathrm{T}}=0.21 \%$, the slope decreases sharply, due to the cracking of filaments. Thus, $\varepsilon_{\mathrm{f}, 1}-\varepsilon_{\mathrm{r}}$ is estimated to be $0.21 \%$, as shown in Fig.5(b). $\varepsilon_{\mathrm{f}, 2}-\varepsilon_{\mathrm{r}}$ (= the strain at which all filaments come to be cracked in a cross-section where cracking of filaments is most advanced) can be estimated from the tensile strain $\varepsilon_{\mathrm{T}}$ at which the slope reaches zero, respectively. Thus, $\varepsilon_{\mathrm{f}, 2}-\mathcal{E}_{\mathrm{r}}$ is estimated to be $0.25 \%$, as shown in Fig.5(b). As $\varepsilon_{\mathrm{r}}$ is $-0.12 \%$ in the present sample [15], $\varepsilon_{\mathrm{f}, 1}$ and $\varepsilon_{\mathrm{f}, 2}$ are estimated to be $0.09 \%$ and $0.13 \%$, respectively.

From the results above, the following three regions can be distinguished, as shown in Fig.5(b): Region 0 (non-damaged region) with the $\varepsilon_{\mathrm{Bi} 2223}$ range of $\varepsilon_{\mathrm{Bi} 2223} \leq \varepsilon_{\mathrm{f}, 1}$, existing in the tensile strain range of $\varepsilon_{\mathrm{T}} \leq \varepsilon_{\mathrm{f}, 1}-\varepsilon_{\mathrm{r}}$, Region 1 (partially damaged region where cracked and non-cracked filaments co-exist) with the $\varepsilon_{\mathrm{Bi} 2223}$ range of $\varepsilon_{\mathrm{f}, 1} \leq \varepsilon_{\mathrm{Bi} 2223}$ $\leq \varepsilon_{\mathrm{f}, 2}$, existing in the tensile strain range of $\varepsilon_{\mathrm{f}, 1}-\mathcal{E}_{\mathrm{r}} \leq \varepsilon_{\mathrm{T}} \leq \varepsilon_{\mathrm{f}, 2}-\varepsilon_{\mathrm{r}}$, and Region 2 (seriously damaged region where multiple cracking of Bi2223 filaments occurs) with the $\varepsilon_{\mathrm{Bi} 2223}$ range of $\varepsilon_{\mathrm{f}, 2} \leq \varepsilon_{\mathrm{Bi} 2223}$, existing in the tensile strain range of $\varepsilon_{\mathrm{f}, 2}-\varepsilon_{\mathrm{r}} \leq \varepsilon_{\mathrm{T}}$.

\subsection{Formulation of the damage evolution in the core}

The Bi2223 filamentary composite is composed of the sheath of Ag alloy and the core in which the filaments are bundled into Ag. Figure 6(a) shows the micrograph of the transverse cross-section of the sample, in which the thickness direction is three times magnified from the as-observed one as to show clearly the shape of the core. The boundary of the core is shown with a broken curve. Figure 6(b) shows the schematic representation of the geometry of the transverse cross-section. $W_{\text {core }}$ and $t$ are the width of the core and thickness of the sample, which have been measured to be $3.90 \mathrm{~mm}$ and $0.23 \mathrm{~mm}$, respectively. The width and thickness directions of the composite tape are taken to be as $x$ and $y$, respectively, and the center of the composite tape as $x=y=0$. The core boundary $y_{\text {core }}$ (ABCDEFGHA) is expressed as a function of $x$ with the following $9^{\text {th }}$ order polynomials [25]. The length unit is millimeters.

$$
\left.\begin{array}{l}
\text { CDE: } \mathrm{y}_{\text {core }}= \\
\begin{array}{rl} 
& 0.060214-0.0405173 x+1.03050 x^{2}-4.05239 x^{3} \\
& +8.94014 x^{4}-12.6431 x^{5}+11.3895 x^{6}-6.22952 x^{7} \\
& +1.87094 x^{8}-0.235769 x^{9} \quad \text { for } 0 \leq x \leq 1.95
\end{array} \\
\text { ABC: symmetry with EDC with respect to } x=0 \\
\text { AHGFE: symmetry with ABCDE with respect to } y=0
\end{array}\right\}
$$


The maximum value of $y_{\text {core, }} y_{\text {core,max }}$, at B and D in Fig.6(b) was $0.101 \mathrm{~mm}$. Under the application of bending strain $\varepsilon_{\mathrm{B}}$, when $\varepsilon_{\mathrm{B}}$ reaches the irreversible bending strain $\varepsilon_{\mathrm{B} \text {,irr, }}$ damage of $\mathrm{Bi} 2223$ filaments takes place first at $y=y_{\text {coremax }}$. Beyond $\varepsilon_{\mathrm{B}, \text { irr }}$, the damage front extends towards $y=0$ (neutral axis) with increasing $\varepsilon_{\mathrm{B}}$, resulting in reduction in critical current. At a given $\varepsilon_{\mathrm{B}}\left(>\varepsilon_{\mathrm{B} \text {,irr }}\right)$, the bending strain-induced tensile strain varies largely along the sample thickness direction $y$ and hence non-damaged-, partially damaged- and seriously damaged regions appear, as follows.

As noted in Subsection 2.1, the present sample is damaged only in the tensile side $(0<y)$ within the bending strain range $0 \sim 0.83 \%[15,25]$. Under the application of bending strain $\left(\varepsilon_{\mathrm{B}} \leq 0.83 \%\right)$, the relation among $y$-coordinate, bending strain $\varepsilon_{\mathrm{B}}$, sample thickness $t$ and the strain $\varepsilon_{\mathrm{Bi} 22223}$ of the filaments in longitudinal direction under bending strain is expressed as $[14,16,17]$

$$
\varepsilon_{\mathrm{Bi} 2223}=\varepsilon_{\mathrm{B}} y /(t / 2)+\varepsilon_{\mathrm{r}}
$$

Though Eq.(3) is not rigid, it has been shown that, by using Eq.(3), experimental results of $I_{\mathrm{c}}-\varepsilon_{\mathrm{B}}$ relation for many different fabrication route samples can be described successfully [14-17, 24-26]. Equation (3) is a useful tool practically.

$\varepsilon_{\text {Bi2223 }}$ increases with increasing $y$ from $\varepsilon_{\mathrm{r}}(=-0.12 \%)$ at $y=0$ to $\varepsilon_{\mathrm{B}}+\varepsilon_{\mathrm{r}}$ at $y=t / 2$. As has been shown in Subsection 4.1, Bi2223 filaments are cracked first at $\varepsilon_{\mathrm{Bi} 2223}=\varepsilon_{\mathrm{f}, 1}=$ $0.09 \%$ and are cracked seriously at $\varepsilon_{\mathrm{Bi} 2223}=\varepsilon_{\mathrm{f}, 2}=0.13 \%$ under tensile strain. Noting the $y$-positions at $\varepsilon_{\mathrm{Bi2} 223}=\varepsilon_{\mathrm{f}, 1}$ and $\varepsilon_{\mathrm{f}, 2}$ as $y_{1}$ and $y_{2}$, respectively, we can obtain the $y_{1^{-}}$and $y_{2}-$ values for a given $\varepsilon_{\mathrm{B}}$ by substituting $\varepsilon_{\mathrm{Bi} 2223}=\varepsilon_{\mathrm{f}, 1}=0.09 \%$ and $\varepsilon_{\mathrm{Bi} 2223}=\varepsilon_{\mathrm{f}, 2}=0.13 \%$, respectively, together with the sample thickness $t=0.23 \mathrm{~mm}$ and $\varepsilon_{\mathrm{r}}=-0.12 \%$, into Eq.(3), as schematically shown in Fig.6(c). The damage situation in the core in the transverse cross-section is shown in Fig.6(b).

The extent of damage in the core is dependent on $y$-position; the regions locating in $-y_{\text {core,max }} \leq y \leq y_{1}, y_{1} \leq y \leq y_{2}$ and $y_{2} \leq y \leq y_{\text {core,max }}$ are non-damaged, partially-damaged and seriously-damaged, respectively. Thus, under bending strain, Regions 0,1 and 2, observed under tensile strain (Fig.5(b)), also appear, and are characterized as follows.

*In Region 0 (non-damaged region locating in $-y_{\text {core,max }} \leq y \leq y_{1}$ ), as the $\varepsilon_{\mathrm{Bi} 2223}$ is lower than $\varepsilon_{\mathrm{f}, 1}$, all filaments transport current and critical current is retained.

*In Region 1 (partially-damaged region locating in $y_{1} \leq y \leq y_{2}$ ), as $\varepsilon_{\mathrm{Bi} 2223}$ is higher than $\varepsilon_{\mathrm{f}, 1}$ and lower than $\varepsilon_{\mathrm{f}, 2}$, cracked and non-cracked filaments co-exist and hence critical current is recued. 
*In Region 2 (seriously-damaged region locating in $y_{2} \leq y \leq y_{\text {core,max }}$ ), as $\varepsilon_{\text {Bi2223 }}$ is higher than $\varepsilon_{\mathrm{f}, 2}$, all filaments are cracked and critical current is almost zero.

It is noted that the bending strains $\varepsilon_{\mathrm{B}, 1}$ and $\varepsilon_{\mathrm{B}, 2}$, at which Regions 1 and 2 appear, are given by $\left(\varepsilon_{\mathrm{f}, 1}-\varepsilon_{\mathrm{r}}\right) /\left\{y_{\text {core,max }} /(t / 2)\right\}$ and $\left(\varepsilon_{\mathrm{f}, 2}-\varepsilon_{\mathrm{r}}\right) /\left\{y_{\text {core,max }} /(t / 2)\right\}$, respectively, from Eq.(3). Substituting $\varepsilon_{\mathrm{f}, 1}-\varepsilon_{\mathrm{r}}=0.21 \%, \varepsilon_{\mathrm{f}, 2}-\varepsilon_{\mathrm{r}}=0.25 \%, t=0.23 \mathrm{~mm}$ and $y_{\text {core, } \max }=0.10 \mathrm{~mm}$ into these relations, we have $\varepsilon_{\mathrm{B}, 1}=0.24 \%$ and $\varepsilon_{\mathrm{B}, 2}=0.28 \% . \varepsilon_{\mathrm{B}, 1}=0.24 \%$ corresponds to the irreversible bending strain $\varepsilon_{\mathrm{B} \text {,irr. }}$. Thus, only Region 0 exists in the bending strain range of $\varepsilon_{\mathrm{B}} \leq \varepsilon_{\mathrm{B}, 1}(0.24 \%)$, Regions 0 and 1 co-exist in the bending strain range of $\varepsilon_{\mathrm{B}, 1}(0.24 \%) \leq \varepsilon_{\mathrm{B}} \leq \varepsilon_{\mathrm{B}, 2}(0.28 \%)$ and all Regions 0,1 and 2 co-exists in the bending strain range of $\varepsilon_{\mathrm{B}} \geq 0.28 \%\left(\varepsilon_{\mathrm{B}, 2}\right)$.

Noting the cross-sectional area of the core as $S_{\text {core }}\left(=0.66 \mathrm{~mm}^{2}\right.$ [25]), the cross-sectional areas of Regions 0,1 and 2 as $\Delta S_{0}, \Delta S_{1}$ and $\Delta S_{2}$, respectively, the $x$-coordinates at the cross-points of $y_{\text {core }}$ (Eq.(1)) with $y_{1}$ as $-x_{1}$ and $x_{1}$, and the

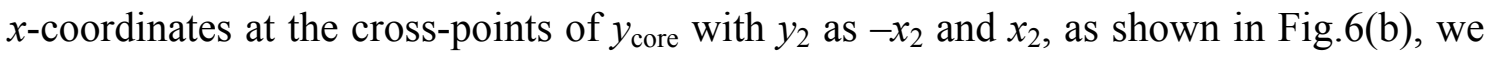
can calculate $\Delta S_{0} / S_{\text {core }}, \Delta S_{1} / S_{\text {core }}$ and $\Delta S_{2} / S_{\text {core }}$ by,

$$
\begin{aligned}
& \Delta S_{0} / S_{\text {core }}=0.5+\left\{\int_{-W \text { core } / 2}^{-x_{1}} y_{\text {core }} \mathrm{d} x+2 x_{1} y_{1}+\int_{x_{1}}^{W_{\text {core }} / 2} y_{\text {core }} \mathrm{d} x\right\} / S_{\text {core }} \\
& \Delta S_{1} / S_{\text {core }}=\left\{\int_{-x 1}^{-x 2}\left(y_{\text {core }}-y_{1}\right) \mathrm{d} x+2 x_{2}\left(y_{2}-y_{1}\right)+\int_{x_{2}}^{x_{1}}\left(y_{\text {core }}-y_{1}\right) \mathrm{d} x\right\} / S_{\text {core }} \\
& \Delta S_{2} / S_{\text {core }}=\int_{-x 2}^{x 2}\left(y_{\text {core }}-y_{2}\right) d x / S_{\text {core }}
\end{aligned}
$$

Figure 7(a) shows the tensile strain $\varepsilon_{\text {Bi2223 }}$ of filaments calculated by Eq.(3) as a function of the normalized $y$-position with respect to the half thickness of the sample, $y /(t / 2)$, at a bending strain of $\varepsilon_{\mathrm{B}}=0.66 \%$ as an example. As $\varepsilon_{\mathrm{f}, 1}$ and $\varepsilon_{\mathrm{f}, 2}$ were $0.09 \%$ and $0.13 \%$, respectively, the corresponding $y_{1} /(t / 2)$ and $y_{2} /(t / 2)$ were 0.32 and 0.38 , respectively. The $y_{\text {coremax }} /(t / 2)$ was 0.88 . Thus, at $\varepsilon_{\mathrm{B}}=0.66 \%$, Regions 0,1 and 2 were in the range of $-0.88 \leq y /(t / 2) \leq 0.32,0.32 \leq y /(t / 2) \leq 0.38$ and $0.38 \leq y /(t / 2) \leq 0.88$, respectively. The solid curve in Fig.7(b) shows the cumulative cross-sectional area $S / S_{\text {core }}$ of the core integrated from $y /(t / 2)=-y_{\text {core,max }} /(t / 2)=-0.88$ to $y /(t / 2)$ as a function of $y /(t / 2)$. The $S / S_{\text {core }}$ values at $y_{1} /(t / 2)=0.32$ and $y_{2} /(t / 2)=0.38$ were 0.71 and 0.75 , respectively. The fractions of cross-sectional area of Region $0\left(\Delta S_{0} / S_{\text {core }}=0.71\right)$, Region $1\left(\Delta S_{1} / S_{\text {core }}=0.04\right)$ and Region $2\left(\Delta S_{2} / S_{\text {core }}=0.25\right)$ in the specimen bent by $\varepsilon_{\mathrm{B}}=0.66 \%$ are also shown in Fig.7(b). In this way, by using the $\varepsilon_{\mathrm{f}, 1^{-}}$and $\varepsilon_{\mathrm{f}, 2^{-}}$values obtained from the 
tensile stress-strain curve, the area fraction of each Region is calculated when a bending strain is given.

Figure 8 shows the calculated change in fraction of cross-sectional area of Region $0\left(\Delta S_{0} / S_{\text {core }}\right)$, Region $1\left(\Delta S_{1} / S_{\text {core }}\right)$ and Region $2\left(\Delta S_{2} / S_{\text {core }}\right)$ as a function of bending strain $\varepsilon_{\mathrm{B}}$. In the bending strain range up to $\varepsilon_{\mathrm{B}}=\varepsilon_{\mathrm{B}, 1}\left(=\varepsilon_{\mathrm{B} \text {,irr }}=0.24 \%\right)$ where filaments are not cracked, $\Delta S_{0} / S_{\text {core }}$ remains 1 (unity). Only Region 0 exists. Region 1 appears at $\varepsilon_{\mathrm{B}}$ $=\varepsilon_{\mathrm{B}, 1}=0.24 \%$ and then Region 2 appears at $\varepsilon_{\mathrm{B}}=\varepsilon_{\mathrm{B}, 2}=0.28 \%$. The calculation results in Fig.8 shows that the fraction of cross-sectional area of Region $1, \Delta S_{1} / S_{\text {core, }}$, is small, being less than 0.07 , in the whole bending strain range calculated, while that of Region 2, $\Delta S_{1} / S_{\text {core }}$, increases with increasing $\varepsilon_{\mathrm{B}}$ and reaches around 0.30 at $\varepsilon_{\mathrm{B}}=0.83 \%$.

\subsection{Estimation of current amount transported by each region}

The core is composed of parallel circuit of Regions 0,1 and 2. Noting the critical current and $n$-value of Region $i(i=0,1$ and 2$)$ as $I_{\mathrm{c}, i}$ and $n_{i}$, respectively, we can express the total current $I$ as

$$
I=\sum_{i=0}^{2} I_{\mathrm{c}, i}\left(\Delta S_{i} / S_{\text {core }}\right)\left(V / L E_{\mathrm{c}}\right)^{1 / n_{i}}
$$

The current $I_{i}$ transported by Region $i$ is calculated by

$$
I_{i}=I_{\mathrm{c}, i}\left(\Delta S_{i} / S_{\text {core }}\right)\left(V / L E_{\mathrm{c}}\right)^{1 / n_{i}}
$$

As the values of $\Delta S_{0} / S_{\text {core }}, \Delta S_{1} / S_{\text {core }}$ and $\Delta S_{2} / S_{\text {core }}$ at various bending strains have been obtained as shown in Fig.8, $V-I$ curves of the specimen and of each region can be calculated with Eqs.(7) and (8) when the $I_{\mathrm{c}, \mathrm{i}^{-}}$and $n_{\mathrm{i}^{-}}$values characterizing Region $i$ are given. In this work, $I_{\mathrm{c}, 0}$ and $n_{0}$ for Region 0 were taken to be $70 \mathrm{~A}$ and 18 from the average critical current and average $n$-value measured at $\varepsilon_{\mathrm{B}}=0 \%$, respectively. For Region 1, half of the critical current of the non-damaged state was taken as $I_{\mathrm{c}, 1}(35 \mathrm{~A})$. The corresponding $n$-value, $n_{1}$, was taken to be 6 from the measured $n-I_{\mathrm{c}}$ relation under tensile strain (Fig.4). For Region 2, $I_{\mathrm{c}, 2}$ and $n_{2}$ were taken to be $2.5 \mathrm{~A}$ and 2.9, respectively, from the lowest set of $I_{\mathrm{c}}$ and $n$-values measured under tensile stress (Fig.4).

Figure 9(a) shows the calculated current of Regions $0\left(I_{0}\right), 1\left(I_{1}\right)$ and $2\left(I_{2}\right)$ with increasing total current $I$ at $\varepsilon_{\mathrm{B}}=0.66 \%$ as an example. All of $I_{0}, I_{1}$ and $I_{2}$ increased with total current $I$ and hence with increasing voltage $V$. It is noted that, at any $I$ (and $V$ ), the $I_{0}$ was far higher than $I_{1}$ and $I_{2}$. For instance, the critical current $I_{\mathrm{c}}$ ( $I$ at $E=L / V=1$ $\mu \mathrm{V} / \mathrm{cm}$ ) in this example was $51 \mathrm{~A}$. The values of $I_{0}, I_{1}$ and $I_{2}$ at $E=1 \mu \mathrm{V} / \mathrm{cm}$ were $49 \mathrm{~A}$, 
1.4 A and 0.6 A, respectively. In order to examine whether the same feature is found or not at any bending strain, the variations in $I_{0} / I_{\mathrm{c}}, I_{1} / I_{\mathrm{c}}$ and $I_{2} / I_{\mathrm{c}}$ with bending strain $\varepsilon_{\mathrm{B}}$ were calculated. The result is shown in Fig.9(b). The $I_{0} / I_{\mathrm{c}}$ was higher than 0.95 in the whole bending strain range calculated. The reason for this is attributed to the following features. (i) In Region 1 , the fraction of cross-sectional area $\left(\Delta S_{1} / S\right.$ core $)$ is very small, being less than several percent of the total area of the core (Fig.8), and also the ability of current transportation, $I_{\mathrm{c}, 1}$, is low due to cracked filaments. Accordingly, the product $I_{\mathrm{c}, 1} \times\left(\Delta S_{1} / S_{\text {core }}\right)$ is far smaller than $I_{\mathrm{c}, 0}\left(\Delta S_{0} / S_{\text {core }}\right)$. (ii) In Region 2 , the fraction of cross-sectional area $\left(\Delta S_{2} / S\right.$ core $)$ increases largely in contrast to that of Region 1 (Fig.8) but its contribution to overall current is small since the ability of current transportation, $I_{\mathrm{c}, 2}$, is very low due to the severe damage of filaments and hence $I_{\mathrm{c}, 2} \times\left(\Delta S_{2} / S_{\text {core }}\right)$ is far smaller than $I_{\mathrm{c}, 0}\left(\Delta S_{0} / S_{\text {core }}\right)$.

In this way, current is transported almost by Region 0 despite the co-existence of Regions 0,1 and 2. However, as shown below, the slight decrease in $n$-value with $\varepsilon_{\mathrm{B}}$ (Fig.2(b)) cannot be accounted for if the contribution of either or both of Regions 1 and 2 are neglected.

4.4 Comparison of the $I_{c}-\varepsilon_{B}, n-\varepsilon_{B}$ and $n-I_{c}$ relations obtained by the present modeling analysis with experimental results

In order to examine the influence of Regions 0,1 and 2 on $I_{\mathrm{c}}$ and $n$-value, the following Models were used.

*Model 0+1+2: All Regions 0, 1 and 2 were incorporated in calculation of Eq.(7). The calculation results by this model reflect the superimposed influences of all Regions. In order to distinguish the influence of each Region on $I_{\mathrm{c}^{-}}$and $n$-values, the following Models were additionally used.

*Model 0: As shown in Fig.9(a), the currents at $E=V / L=0.1,1$ and $10 \mu \mathrm{V} / \mathrm{cm}$ are determined mostly by Region 0 . Based on this result, as a first approximation, the contribution only of Region 0 was calculated by neglecting the contribution of Regions 1 and 2. In this model, $I_{\mathrm{c}, 1}$ and $I_{\mathrm{c}, 2}$ were set to be zero in calculation of Eq.(7).

*Model 0+1: In order to detect the influence of Region 1 on the result of Model 0 , the contribution of Region 2 was neglected by setting $I_{\mathrm{c}, 2}=0$ in calculation of Eq.(7).

Model 0+2: In order to detect the influence of Region 2 on the result of Model 0 , the contribution of Region 1 was neglected by setting $I_{\mathrm{c}, 1}=0$ in calculation of Eq.(7).

Substituting the values of $I_{\mathrm{c}, i}$ and $n_{i}(i=1,2$ and 3) stated above for each model and the values of $\Delta S_{i} / S_{\text {core }}$ at each bending strain $\varepsilon_{\text {B }}$ (Fig.8) into Eq.(7), $V-I$ curve at each bending strain was calculated, from which $I_{\mathrm{c}}$ and $n$-value at each bending strain were 
obtained with the same criteria as in experiment. The calculated $I_{\mathrm{c}}-\varepsilon_{\mathrm{B}}$ relation, $n-\varepsilon_{\mathrm{B}}$ relation and correlation of $n$-value to $I_{\mathrm{c}}$ are shown in Fig. 10 where the experimental results (average $I_{\mathrm{c}}$ and $n$-value at each bending strain) are also shown for comparison. The following features are read from Fig.10.

(i) The experimental result on change in $I_{\mathrm{c}}$ values with $\varepsilon_{\mathrm{B}}$ is described satisfactorily by all Models (Fig.10(a)). This result is attributed to the significant contribution of Region 0 which transports current more than around $95 \%$ of total current at any $\varepsilon_{\mathrm{B}}$ (Fig.9(b)). The contributions of Regions 1 and 2 to $I_{\mathrm{c}}$-values were minor, due to small cross-sectional area of Region 1 and due to almost lost superconductivity of Region 2.

(ii) The experimental result on change in $n$-value with $\varepsilon_{\mathrm{B}}$ (Fig.10(b)) and on $n-I_{\mathrm{c}}$ relation (Fig.10(c)) cannot be described by Model 0 that leads to no change in $n$-value. Model 0 is useful for description of change in $I_{\mathrm{c}}$ with $\varepsilon_{\mathrm{B}}$ due to the reason mentioned in (i) above but not for description of damage-induced change in $n$-value.

(iii) Model $0+1$ describes the slight decrease in $n$-value in relatively high $I_{\mathrm{c}}$ range (low $\varepsilon_{\mathrm{B}}$ range), where the extent of damage is low and only Region 1 exists. In the narrow $\varepsilon_{\mathrm{B}}$ range ( $0 \sim 0.3 \%$ in which irreversible bending strain $\varepsilon_{\mathrm{B}, \text { irr }}=0.24 \%$ is included), this model is useful for description of $n$-value, but not for higher $\varepsilon_{\mathrm{B}}$ range where Region 2 appears. It is noted that, though Region 1 transports only small portion (less than 4\%) of the current (Fig.9(b)), it acts to reduce $n$-value (Fig.10(b,c)). The slight increase in $n$-value with increasing $\varepsilon_{\mathrm{B}}$ in this model is attributed to the decrease in $\Delta S_{1} / S_{\text {core }}$ at high $\varepsilon_{\mathrm{B}}$ range (Fig.8).

(iv) The calculation result of Model $0+2$ shows that, while Region 2 transports current very little (Fig.9(b)), it acts to reduce $n$-value as well as Region 1 (Fig.10(b,c)). Model $0+2$ describes the trend of decrease in $n$-value with $\varepsilon_{\mathrm{B}}$ in the relatively low $I_{\mathrm{c}}$ range (high $\varepsilon_{\mathrm{B}}$ range) but cannot describe the decrease in $n$-value in low $\varepsilon_{\mathrm{B}}$ range below $\varepsilon_{\mathrm{B}, 2}(0.28 \%)$ and also in the $\varepsilon_{\mathrm{B}}$ range just beyond $\varepsilon_{\mathrm{B}, 2}$, for instance at $\varepsilon_{\mathrm{B}}=0.34 \%$. Also, the $n$-value calculated by this model is slightly higher than the experimental results in the whole range of $\varepsilon_{\mathrm{B}}$. In this way, both Model $0+1$ and Model $0+2$ cannot fully describe the change in $n$-value with $\varepsilon_{\mathrm{B}}$ and $n-I_{\mathrm{c}}$ relation.

(v) Model $0+1+2$ describes satisfactorily the decrease in $n$-value with $\varepsilon_{\mathrm{B}}$ in the whole $\varepsilon_{\mathrm{B}}$ range investigated (Fig.10(a,b)) and the slight decrease in $n$-value with decreasing $I_{\mathrm{c}}$ (Fig.10(c)). This means that superimposed influences of both Region 1 and Region 2 contribute to the damage-induced decrease in $n$-value.

In the present work, a model composed of three regions (Regions 0,1 and 2) was used as a first step for description of $I_{\mathrm{c}}-\varepsilon_{\mathrm{B}}, n-\varepsilon_{\mathrm{B}}$ and $n-I_{\mathrm{c}}$ relations of bent-damaged 
Bi2223 tape. The approach was rough but could describe the experimental results satisfactorily. When modified as to include more regions with different extent of damage, it could be refined, and could be a useful tool for prediction especially of $n-\varepsilon_{\mathrm{B}}$ and $n-I_{\mathrm{c}}$ relations from the tensile data (tensile stress- strain curve, and $I_{\mathrm{c}^{-}}$and $n$-values measured under tensile strain).

\section{Conclusions}

(1)The $n$-value of the bent-damaged Bi2223 filamentary composite tape decreased rather slightly with increasing bending strain and with decreasing critical current, in comparison with that of tension-damaged tape.

(2) To describe the experimental result above, a damage evolution model, which combines the steep tensile strain-variation along the thickness direction, shape of the core and the damage strain parameters obtained by the analysis of the tensile stress-strain curve, was proposed.

(3) The measured change in $n$-value and critical current with bending strain and the relation of $n$-value to critical current were described satisfactorily by the present approach.

(4) While the current is changed mainly by the decrease in cross-sectional area of the non-damaged region, the $n$-value is changed by co-existent non-damaged-, partially damaged- and seriously damaged regions.

\section{Acknowledgements}

The authors wish to express their gratitude to The Ministry of Education, Culture, Sports, Science, and Technology, Japan for the grant-in-aid (no. 22360281).

\section{References}

[1] Kagiyama T, Yamazaki K, Kikuchi M, Yamade S, Nakashima T, Kobayashi S, Hayashi K, Sato K, Shimoyama J, Inoue M, Higashikawa K, Kiss T, Kitaguchi H and Kumakura H 2011 IOP Conf. Series: Mater. Sci. Eng. 18152001.

[2] Savvides N; Herrmann J, Reilly D, Muller K-H, Darmann F, McCaughey G, Zhao R and Apperly M 1998 Physica C 306 129-35.

[3] Vase P, Flükiger R, Leghissa M and Glowacki B 2000 Supercond. Sci. Technol. 13 R71-84. 
[4] Kitaguchi H, Itoh K, Kumakura H, Takeuchi T, Togano K and Wada H 2001 IEEE Trans. Appl. Supercond. 11 3058-61.

[5] Passerini R, Dhalle’ M, Giannini E, Witz G, Seeber B and Flükiger R 2002 Physica C 371 173-84.

[6] Weijers H W, Schwartz J and ten Haken B 2002 Physica C 372-376 1364-7.

[7] Ochiai S, Nagai T, Okuda H, Oh S S, Hojo M, Tanaka M, Sugano M and Osamura K 2003 Supercond. Sci. Technol. 16 988-94.

[8] Shin H S and Katagiri K 2003 Supercond. Sci. Technol. 16 1012-8.

[9] Katagiri K, Shin H S, Kasaba K, Tsukinokizawa T, Hiroi K, Kuroda T, Itoh K and Wada H 2003 Supercond. Sci. Technol. 16 995-9.

[10] Hojo M, Nakamura M, Matsuoka T, Tanaka M, Ochiai S, Sugano M and Osamura K 2003 Supercond. Sci. Technol. 16 1043-51.

[11] van der Laan D C, van Eck H J N, ten Haken B, ten Kate H H J and Schwartz J 2003 IEEE Trans. Appl. Supercond. 13 3534-9.

[12] Otto A, Harley E J and Marson R 2005 Supercond. Sci. Technol. 18 S308-12.

[13] Ochiai S, Rokkaku H, Morishita K, Shin J K, Iwamoto S, Okuda H, Hojo M, Osamura K, Sato M, Otto A, Harley E J and Malozemoff A 2007 Supercond. Sci. Technol. 20 202-10.

[14] Ochiai S, Matsuoka T, Shin J K, Okuda H, Sugano M, Mojo M and Osamura K 2007 Supercond. Sci. Technol. 20 1076-83.

[15] Ochiai S, Shin J K, Iwamoto S, Okuda H, Oh S S, Ha D W and Sato M 2008 J. Appl. Phys. 103123911.

[16] Ochiai S, Shin J K, Okuda H, Sugano M, Hojo M, Osamura K, Kuroda T, Itoh K and Wada H 2008 Supercond. Sci. Technol. 21054002.

[17] Ochiai S, Okuda H, Sugano M, Hojo M and Osamura K 2010 J. Appl. Phys. 107 083904.

[18] Larbalestier D C, Cai X Y, Feng Y, Edelman H, Umezawa A, Riley Jr. G N and Carter W L 1994 Physica C 221 299-303.

[19] Passi J, Kalliohaka T, Korpela A, Söderlund L, Herman P F, Kvitkovic J and Majoros M 1999 IEEE Trans. Appl. Supercond. 9 1598-601.

[20] Wang Y, Xiao L, Lin L, Xu X, Lu Y and Teng Y 2003 Cryogenics 43 71-7.

[21] Kuroda T, Itoh K, Katagiri K, Goldacker W, Hsessler W, ten Haken B, Kiuchi M, Noto N, Ochiai S, Otabe S, Shin H S, Sosnowski J, Weijers H, Wada H and Kumakura K 2005 Physica C 425 111-20.

[22] Wang Y, Dai S, Zhao X, Xiao L, Lin L and Hui D 2006 Supercond. Sci. Technol. 19 1278-81. 
[23] Mbaruku A L and Schwarz J 2007 J. Appl. Phys. 101073913.

[24] Ochiai S, Fujimoto M, Okuda H, Oh S S and Ha D W 2009 J. Appl. Phys. 105 06912.

[25] Ochiai S, Fujimoto M, Shin J K, Okuda H, Oh S S and Ha D W 2009 J. Appl. Phys. 106103916.

[26] Ochiai S, Okuda H, Fujimoto M, Shin J K, Oh S S and Ha D W 2011 Physica C 471 1114-8.

[27] Miyoshi Y, Van Lanen E P A, Dhallé M M and Nijhuits N 2009 Supercond. Sci. Technol. 22085009. 


\section{Figure Captions}

Fig.1 Schematic representation of the test specimen, constituting of 6 sections (S1 to S6) with a length $L=1 \mathrm{~cm}$. 1 to 7 show the positions of the voltage probes. Critical current and $n$-value were measured for each section.

Fig. 2 Change in (a) critical current $I_{\mathrm{c}}$ and (b) $n$-value with bending strain $\varepsilon_{\mathrm{B}}$. In this experiment, bending strain $\varepsilon_{\mathrm{B}}$ was given at room temperature and bent specimen was cooled down to $77 \mathrm{~K}$ at which $I_{\mathrm{c}^{-}}$and $n$-values were measured.

Fig. 3 Change in (a) critical current $I_{\mathrm{c}}$ and (b) $n$-value with tensile stress $\sigma_{\mathrm{T}}$. In this experiment, tensile stress $\sigma_{\mathrm{T}}$ was given at $77 \mathrm{~K}$ and $I_{\mathrm{c}^{-}}$and $n$-values were subsequently measured at $77 \mathrm{~K}$.

Fig.4 Comparison of the relation of $n$-value to critical current $I_{\mathrm{c}}$ measured under bending strain with that measured under tensile stress, where the data under bending strain $\varepsilon_{\mathrm{B}}=0 \sim 0.83 \%$ and the data under tensile stress were taken from Figs. 2 and 3, respectively. The data under bending strain at $\varepsilon_{\mathrm{B}}=1.0 \%$, measured for the same sample with the same procedure as in the present work, were taken from our former work [24].

Fig.5 Tensile stress-strain behavior of the composite tape at room temperature. (a) shows the tensile stress $\left(\sigma_{\mathrm{T}}\right)-\operatorname{strain}\left(\varepsilon_{\mathrm{T}}\right)$ curve at $\varepsilon_{\mathrm{T}}=0 \sim 0.3 \%$. The curve and the strains at yielding of $\mathrm{Ag}(0.05 \%)$ and $\mathrm{Ag}$ alloy $(0.12 \%)$ were taken from our preceding work [14]. Stage I, Stage II and Stage III refer to the deformation stages where Ag, Ag alloy and Bi2223 filaments deform elastically, Ag alloy and Bi2223 filaments deform elastically but Ag deforms plastically, and only Bi2223 filaments deform elastically, respectively. Damage (cracking of filaments) initiates and evolutes in the range surrounded by the rectangle in Stage III. (b) shows the change in slope $\sigma_{\mathrm{T}} / \varepsilon_{\mathrm{T}}$ with tensile strain $\varepsilon_{\mathrm{T}}$, obtained from the stress-strain curve in the range surrounded by the rectangle in (a), and the estimated values of $\varepsilon_{\mathrm{f}, 1}-\varepsilon_{\mathrm{r}}, \varepsilon_{\mathrm{f}, 2}-\varepsilon_{\mathrm{r}}, \varepsilon_{\mathrm{f}, 1}$ and $\varepsilon_{\mathrm{f}, 2}$. Region 0 , Region II and Region III refer to the non-damaged, partially damaged and seriously damaged regions, respectively.

Fig.6 Damage evolution in the core. (a) shows the optical micrograph, in which the thickness direction is 3 times magnified from the as-observed one. The scales $(200 \mu \mathrm{m}$ and $600 \mu \mathrm{m})$ are given in actual length. The broken curve shows the boundary of the core in which Bi2223 filaments are bundled into. (b) Schematic representation of the 
shape of the core. (c) Schematic representation of the relation of $y$ to the tensile strain $\varepsilon_{\mathrm{Bi2223}}$ of Bi2223 filaments in composite tape. In (b) and (c), $y_{1}$ and $y_{2}$ refer to the $y$-coordinates at $\varepsilon_{\mathrm{Bi} 2223}=\varepsilon_{\mathrm{f}, 1}$ and $\varepsilon_{\mathrm{f}, 2}$, respectively. Region $0\left(-y_{\text {core,max }}<y<y_{1}\right)$, Region 1 $\left(y_{1}<y<y_{2}\right)$ and Region $2\left(y_{2}<y<y_{\text {coremax }}\right)$ refer to the non-damaged-, partially damaged- and seriously damaged- regions in the core, respectively.

Fig.7 (a)Strain $\varepsilon_{\mathrm{Bi} 2223}$ of Bi2223 filaments in the composite tape as a function of $y$-position normalized with respect to $t / 2, y /(t / 2)$, and the ranges of Regions 0,1 and 2, in the specimen bent by $\varepsilon_{\mathrm{B}}=0.66 \%$, where $y /(t / 2)=0, y_{1} /(t / 2)$ and $y_{2} /(t / 2)$ refer to the normalized $y$-position at $\varepsilon_{\mathrm{Bi} 2223}=\varepsilon_{\mathrm{r}}(-0.12 \%), \varepsilon_{\mathrm{f}, 1}(0.09 \%)$ and $\varepsilon_{\mathrm{f}, 2}(0.13 \%)$, respectively. (b)Cumulative cross-sectional area $S / S_{\text {core }}$ of the core integrated from $y /(t / 2)=$ $-y_{\text {core, } \max } /(t / 2)=-0.88$ to $y /(t / 2)$ as a function of $y /(t / 2)$ and the fractions of the cross-sectional area of Regions $0\left(\Delta S_{0} / S_{\text {core }}\right)$, Region $1\left(\Delta S_{1} / S_{\text {core }}\right)$ and Region $2\left(\Delta S_{2} / S_{\text {core }}\right)$ in the specimen bent by $\varepsilon_{\mathrm{B}}=0.66 \%$.

Fig.8 Change in fraction of cross-sectional area of Region $0\left(\Delta S_{0} / S_{\text {core }}\right)$, Region 1 $\left(\Delta S_{1} / S_{\text {core }}\right)$ and Region $2\left(\Delta S_{2} / S_{\text {core }}\right)$ with increasing bending strain $\varepsilon_{\mathrm{B}}$.

Fig.9 (a) Calculated current of Region $0\left(I_{0}\right)$, Region $1\left(I_{1}\right)$ and Region $2\left(I_{2}\right)$ with increasing total current $I$ at $\varepsilon_{\mathrm{B}}=0.66 \%$ as an example. (b) Calculated variation in $I_{0} / I_{\mathrm{c}}$, $I_{0} / I_{\mathrm{c}}$ and $I_{2} / I_{\mathrm{c}}$ with bending strain $\varepsilon_{\mathrm{B}}$.

Fig. 10 Comparison of the calculated (a) $I_{\mathrm{c}}-\varepsilon_{\mathrm{B}}$, (b) $n-\varepsilon_{\mathrm{B}}$ and (c) $n-I_{\mathrm{c}}$ relations by Model 0 , Model $0+1$, Model $0+2$ and Model $0+1+2$ with experimental results. 


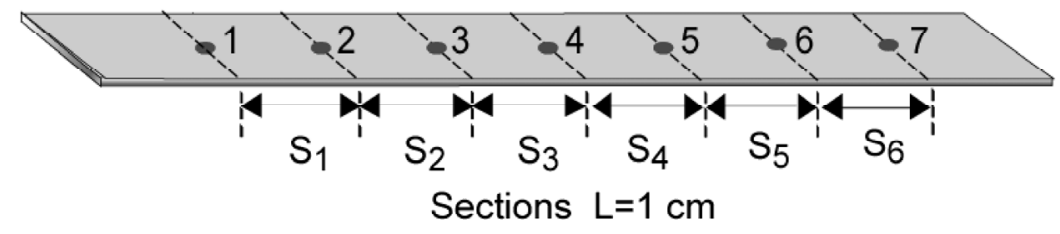

Fig.1
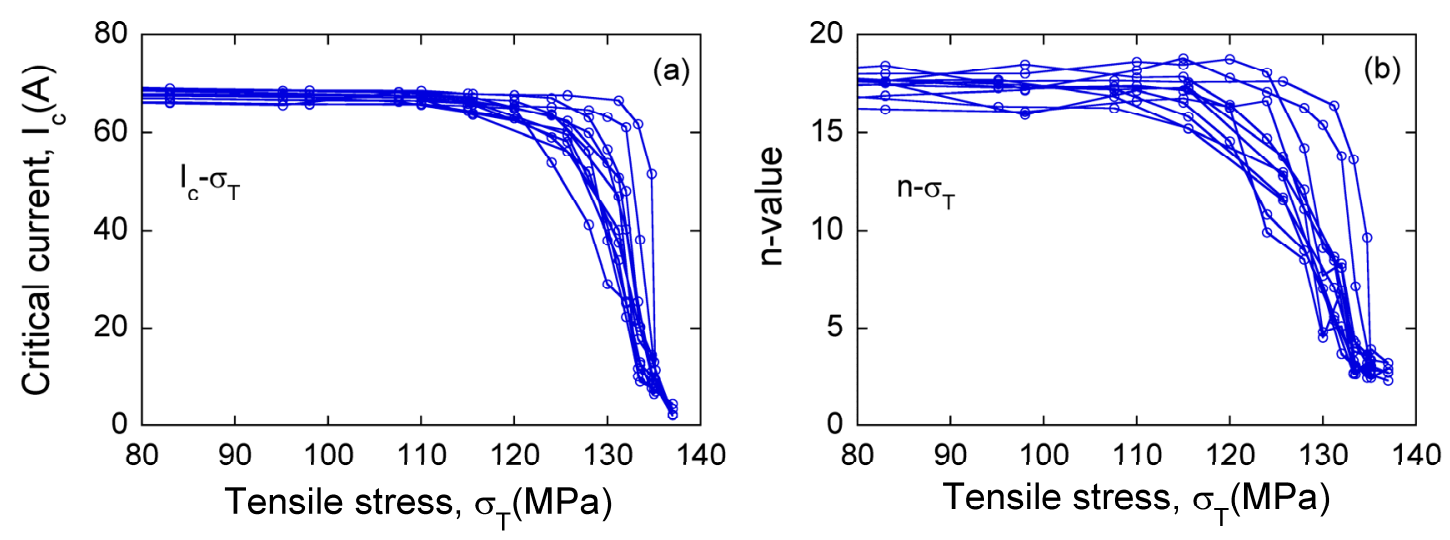

Fig. 2 

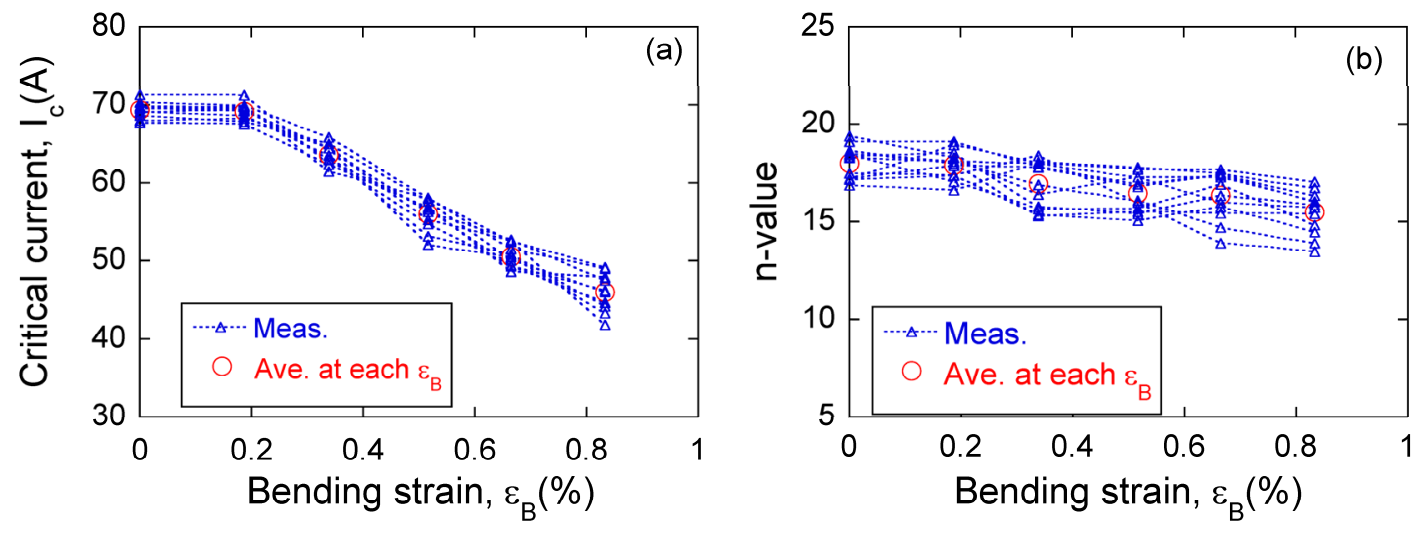

Fig.3

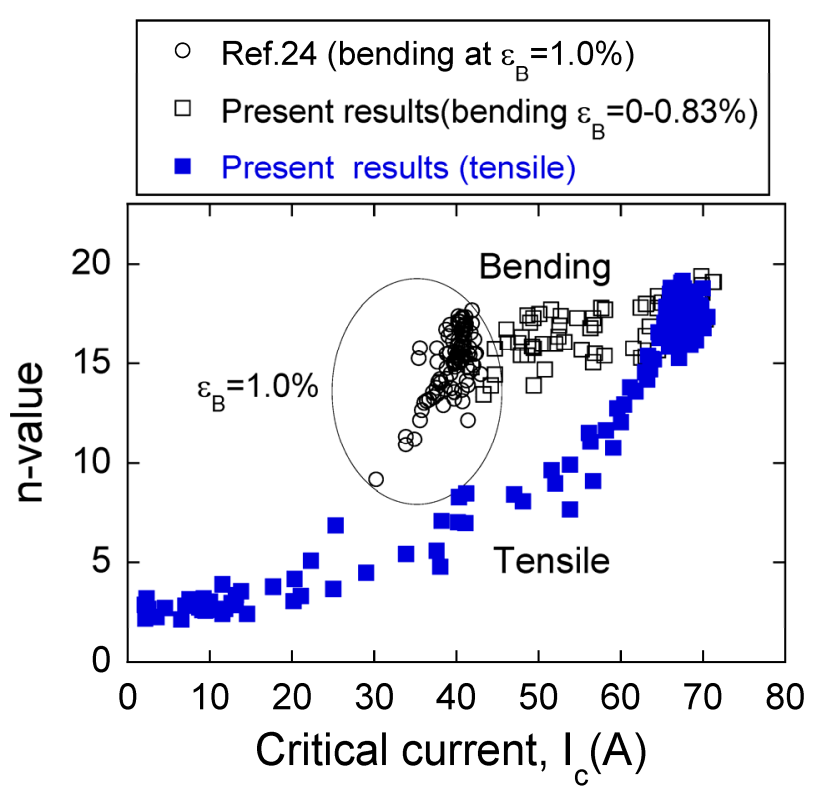

Fig.4 

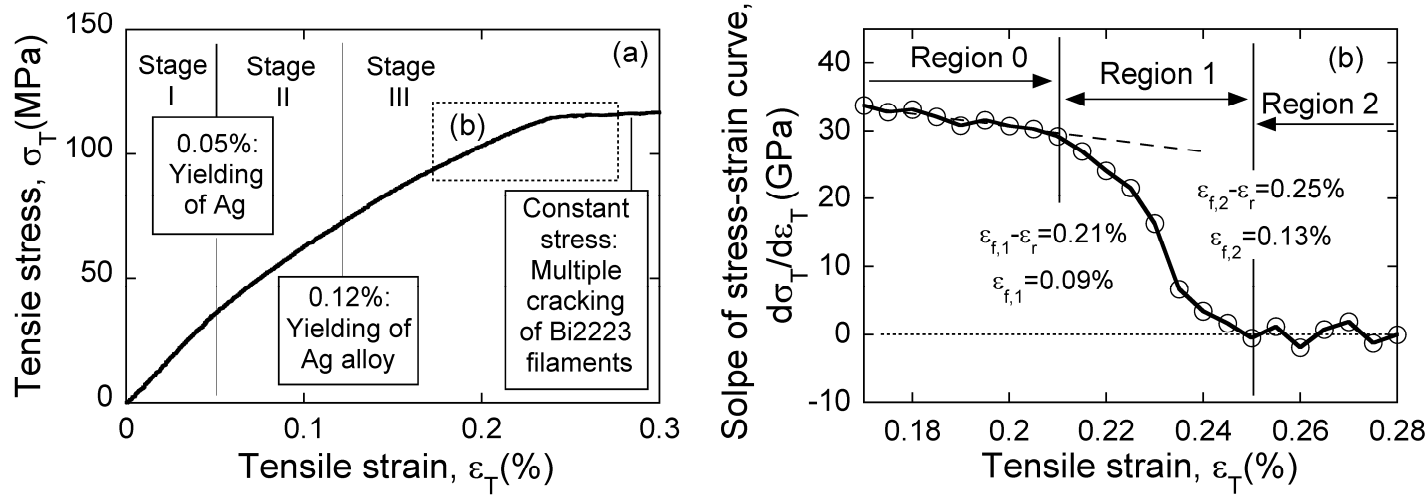

Fig.5
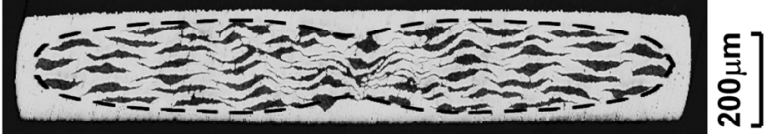

(a)

$600 \mu \mathrm{m}$
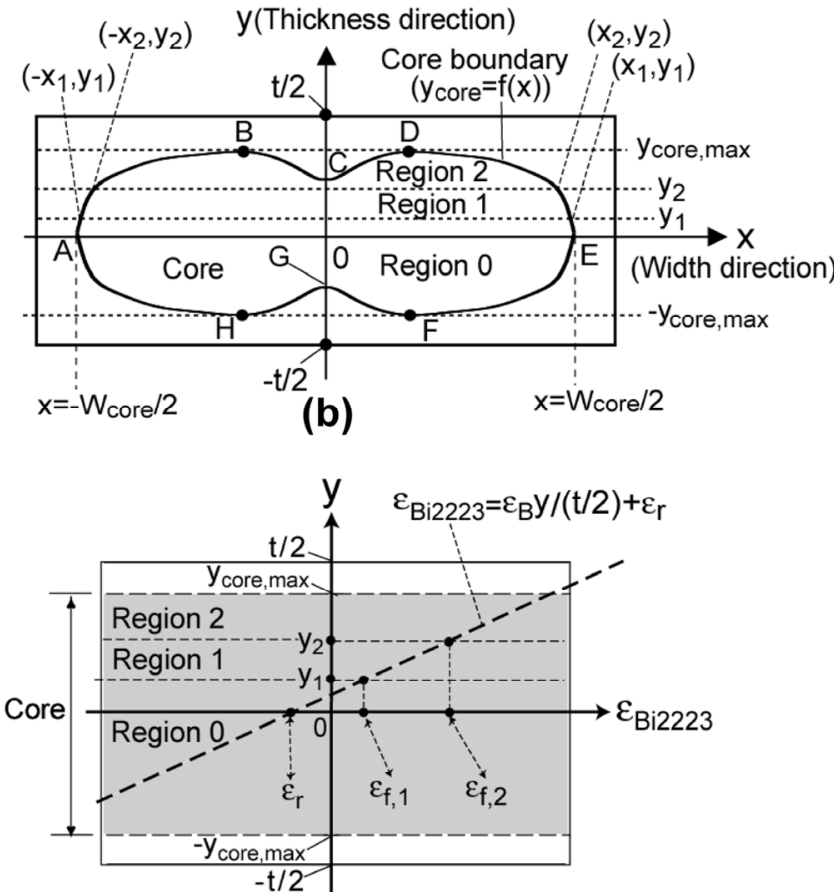

(c)

Fig.6 

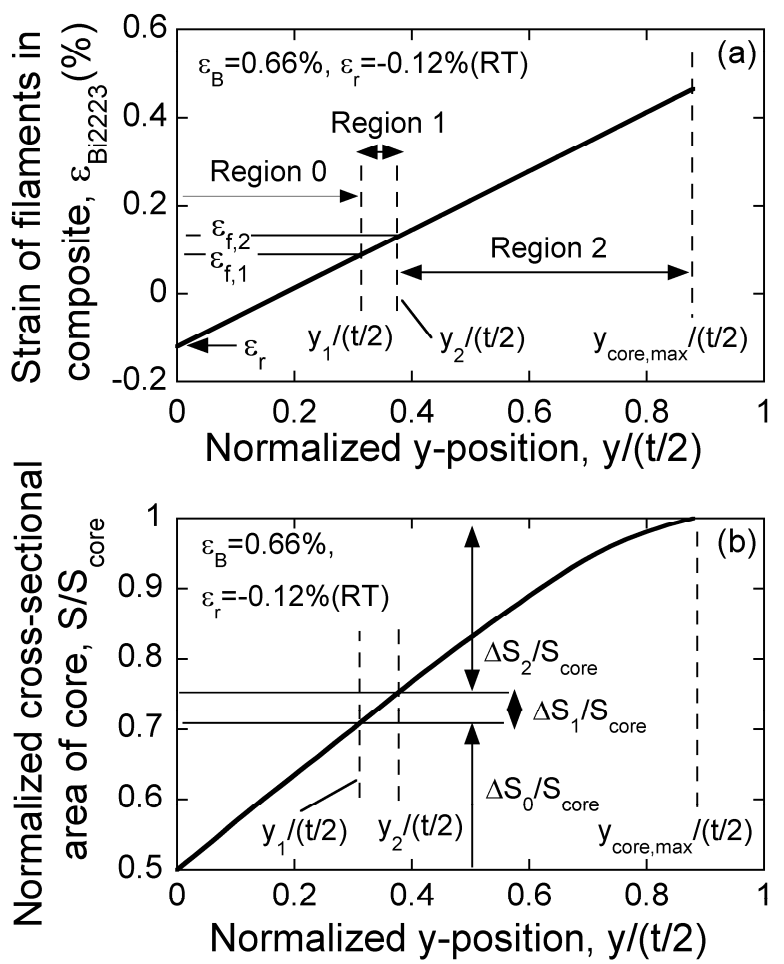

Fig.7

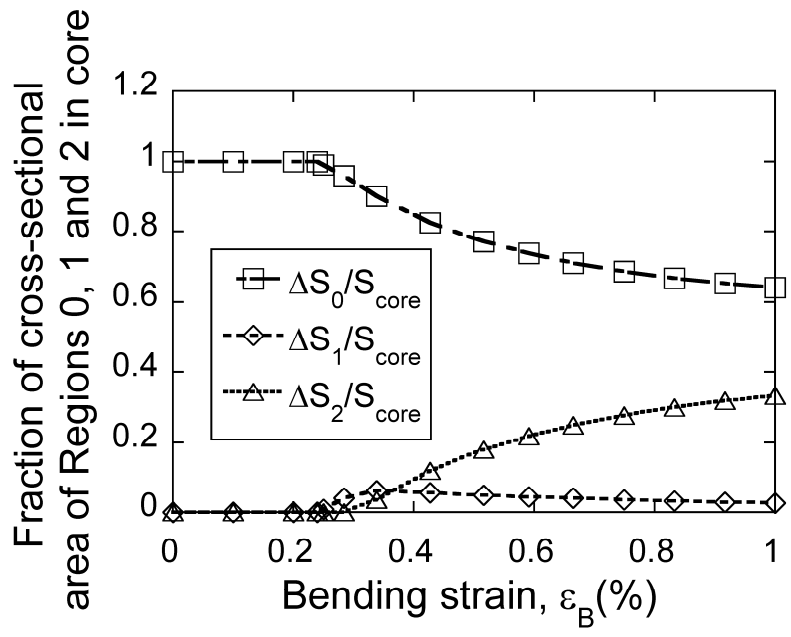

Fig. 8 

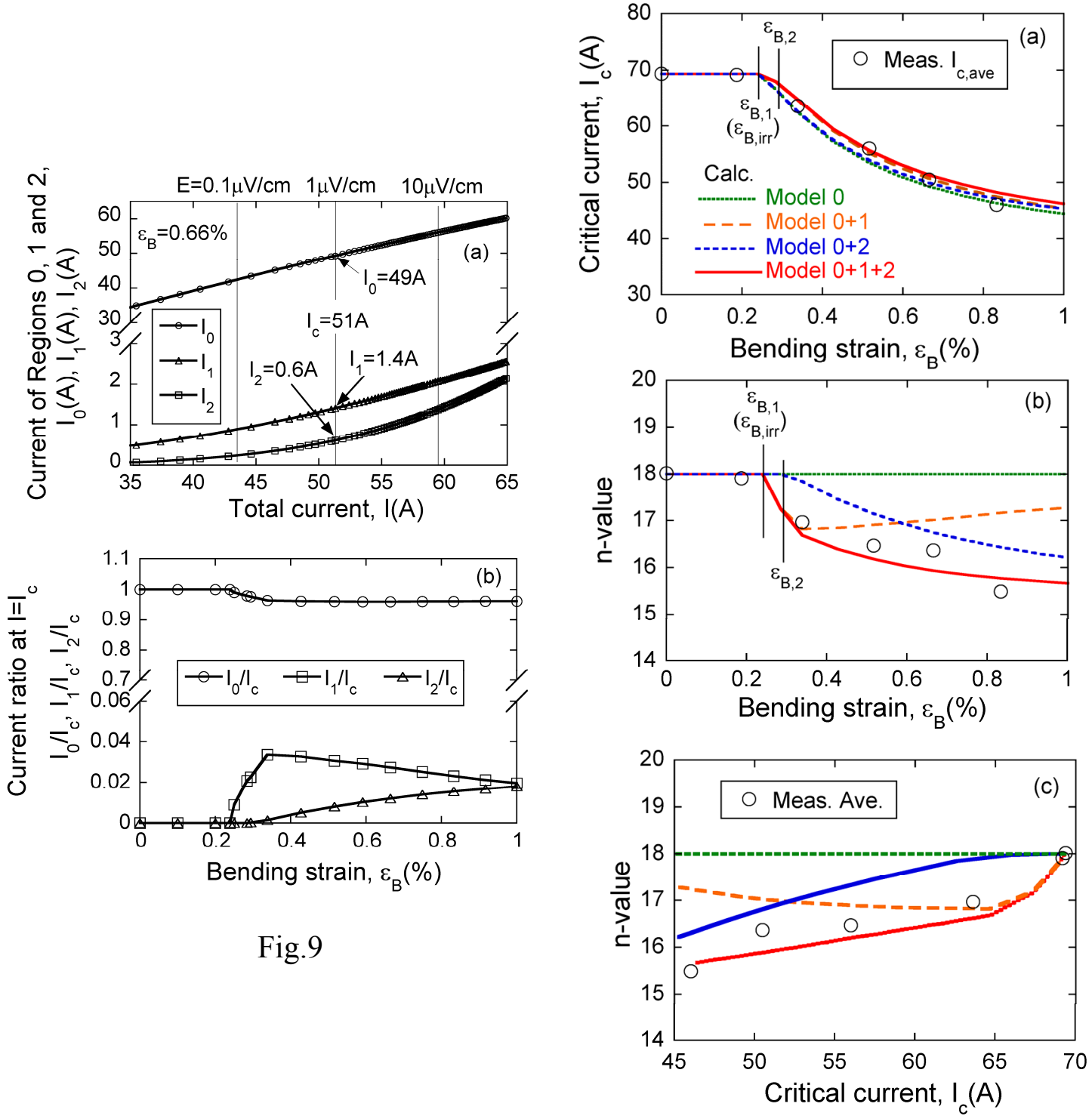

Fig. 10 